\title{
Leben mit der Datenflut
}

Big Data ist kein Hype sondern eine Tatsache, mit der sich Unternehmen aktiv auseinandersetzen müssen. Big Data also besonders große Datenmengen, die mithilfe von Standard-Datenbanken und Daten-Management-Tools nicht oder nur unzureichend verarbeitet werden können - ist heute allgegenwärtig.

Das liegt unter anderem daran, dass diese Daten in zunehmendem Maße maschinell erzeugt werden. Protokolle von Telekommunikationsverbindungen, Web-Zugriffe oder etwa die automatische Erfassung durch RFID-Leser sorgen für einen enormen stetigen Strom an Echtzeitdaten. Wie man diese Da-

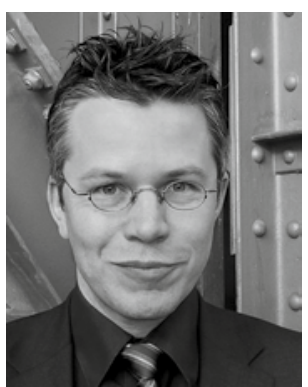

Peter Pagel Chefredakteur ten sinnvoll nutzen kann und welche Tools dabei helfen, erfahren Sie in unserem Schwerpunktthema.

Zum Schluss möchten wir uns für das überwiegend positive und konstruktive Feedback zu unserem ersten Heft 2013 bedanken. Ein neues Layout ist immer ein Schritt ins Unbekannte und es freut uns alle sehr, dass es Ihnen gefällt, wie wir die Wirtschaftsinformatik \& Management weiterentwickelt haben. Vieles von dem, was Sie jetzt im Heft sehen, ist als Reaktion auf Ihre Verbesserungsvorschläge entstanden. Zögern Sie also nicht, sich auch in Zukunft bei uns zu melden, wenn Sie Ideen haben, auf welche Weise wir die Wirtschaftsinformatik \& Management noch besser machen können.

Viele Grüße,

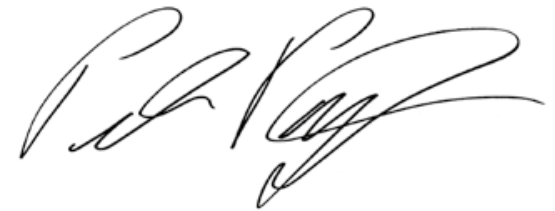

Peter Pagel, Chefredakteur 